
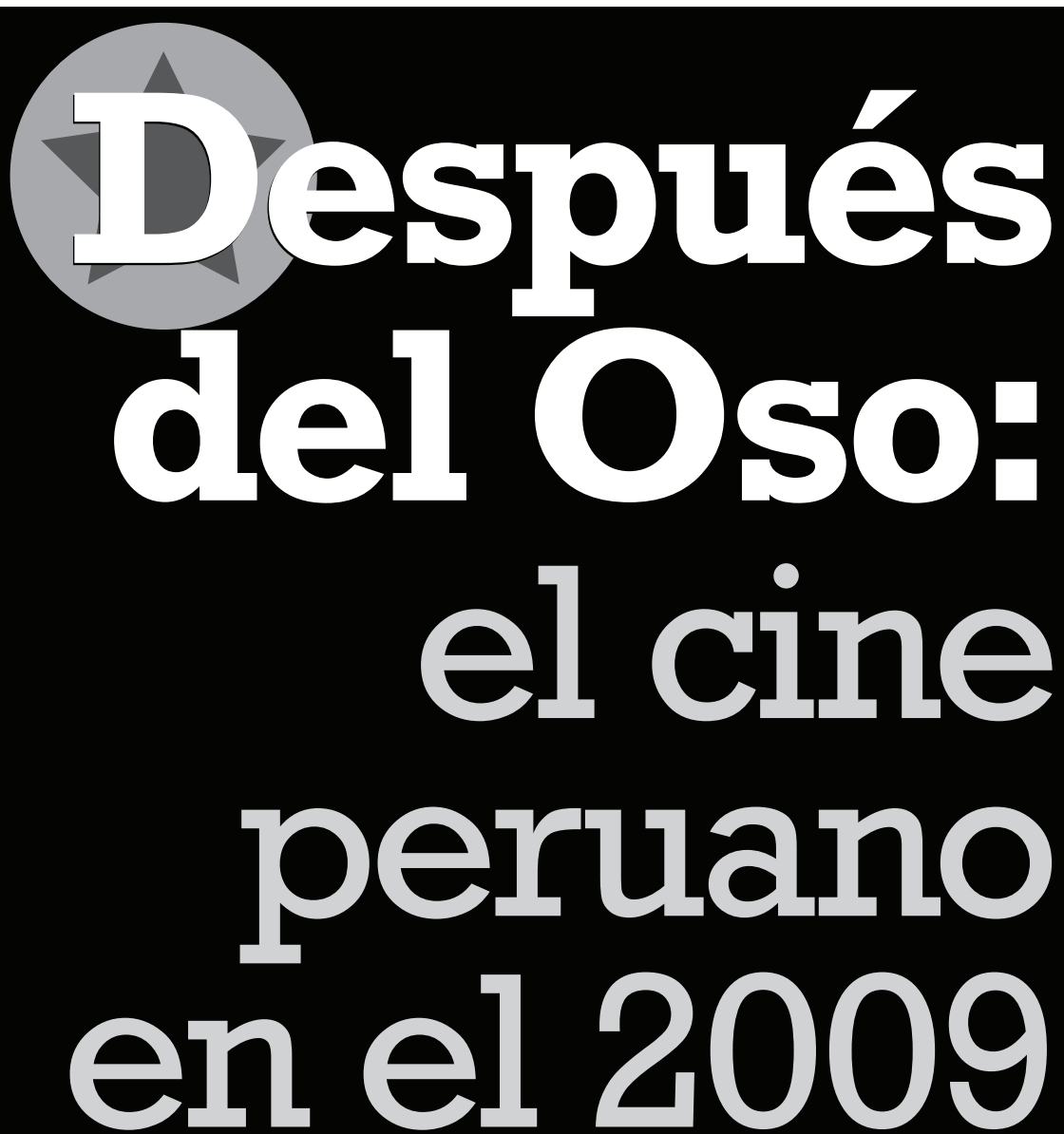

Los balances sobre el cine peruano del año 2009 han traído una larga cola. Que si los premios de Conacine tal cosa, que si la película del Grupo 5 es mejor que Tarata, que después de La teta asustada todo es desolación y barbarie. ¿Es tanto así la situación? ¿Tan terrible es el panorama post “teta"? ¿No será que el prejuicio sobre el cine peruano está ganando la batalla? l cine peruano del 2009 estuvo signado por un hecho muy importante: el Oso de Oro otorgado a La teta asustada, la lograda cinta de Claudia Llosa, un premio que ha permitido, mal que bien, que se comience a hablar y pensar sobre el cine peruano y sus mecanismos de producción. No solo existen dos proyectos de ley en el Congreso que tienen que ver con el cine (las famosas leyes "Peralta" y "Raffo") y con mecanismos que permitan un mayor dinamismo en la producción, sino que además los balances de fin de año han traído cuestionamientos hacia el funcionamiento del Consejo Nacional de Cinematografía (Conacine), debido a los resultados artísticos de las películas que el ente ha premiado.

Lo cierto es que la labor de Conacine en los últimos años ha sido bastante activa: entre el 2005 y el 2010 se han realizado 13 concursos, entre premios a proyectos de todo el país, premios de posproducción y de exhibición. Se pueden cuestionar los criterios de los jurados para premiar las obras que obtuvieron el financiamiento, pero de ahí a decir, como se ha estado insinuando, que hay una especie de mal manejo o de argolla en la labor de Conacine hay un gran trecho.

El año pasado se estrenaron siete largometrajes en salas. Hay que precisar que hubo exhibiciones de algunas películas peruanas hechas de forma casi marginal, sin ningún tipo de apoyo por parte del Estado o de una productora importante, como es el caso de Los actores de Omar Forero o Encierro de Fernando Montenegro. Quizá habría que encontrar mecanismos para que películas concluidas puedan tener algún apoyo estatal en el tema de la exhibición, para que de esta forma el cine que se hace en los márgenes pueda tener una ventana para ser visto.

Sin embargo, se ha estado hablando de las películas financiadas por Conacine como si formaran parte de una miniindustria que se opone al cine realizado en los márgenes. Como si el hecho de que tanto La teta asustada, Tarata y Cu4tro reciban apoyo del Estado hiciera no solo que sus formas de producción fueran exactamente las mismas, sino que, además, artísticamente dieran lo mismo. Y es evidente que no es así: por un lado, aquí cada productor hace lo que puede para sacar adelante una película, ya sea para producirla como 

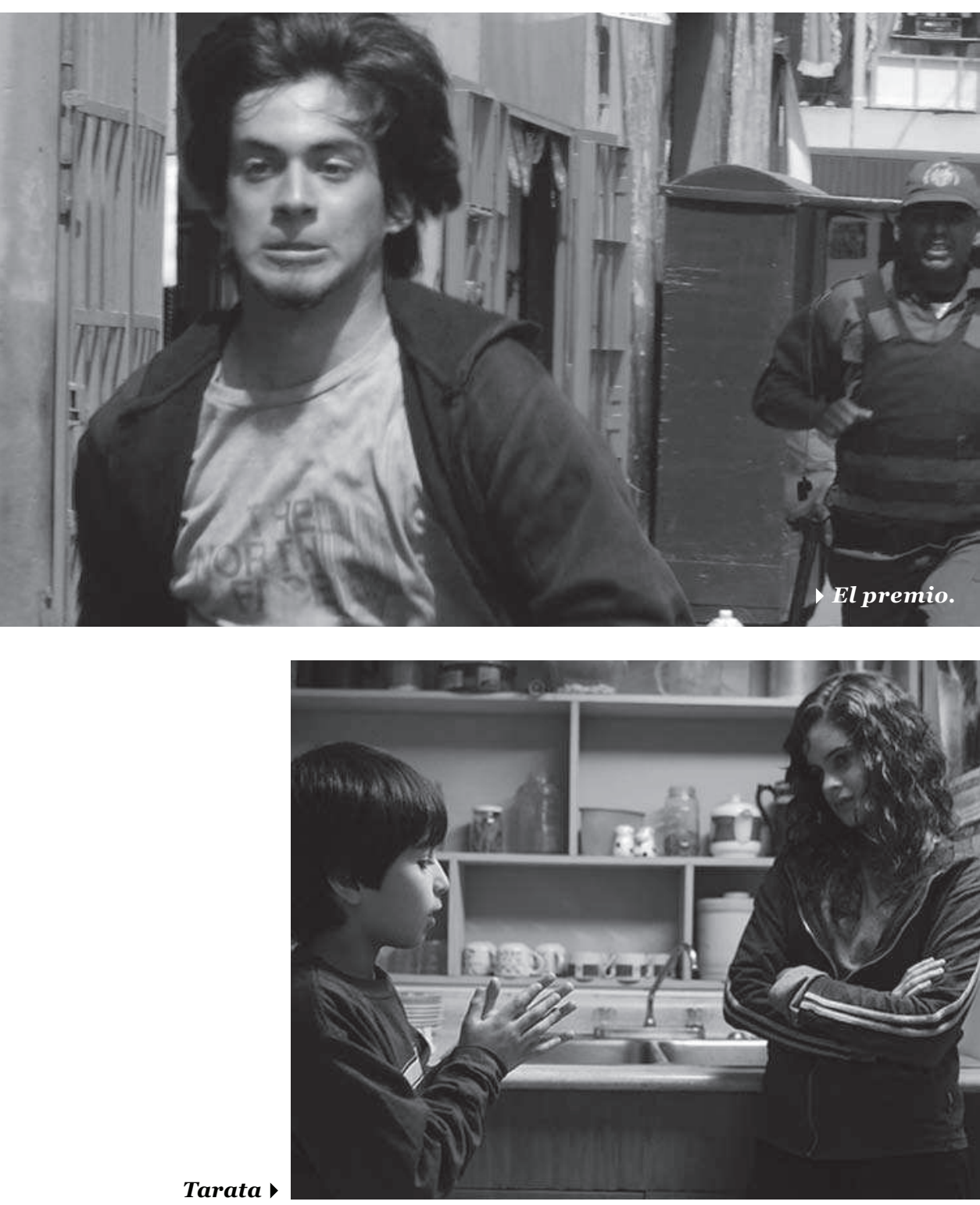

Tarata

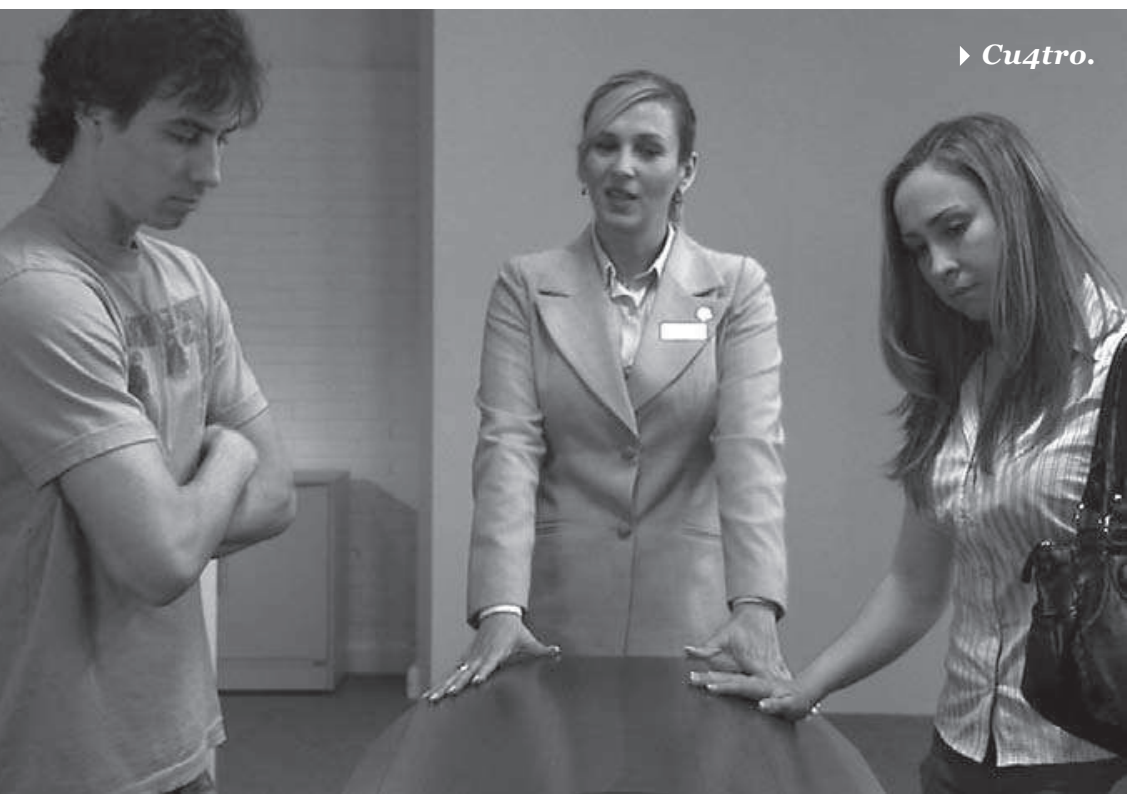

para distribuirla. La del Conacine puede ser una ayuda, pero no acaba con los problemas que tienen las películas para terminarse y estrenarse. No hay mecanismos automatizados, como sí los hay en los países con una industria cinematográfica. Pero, además, decir que todas las películas financiadas en parte por el Conacine son malas y que las realizadas en los márgenes son buenas demuestra un grado de generalización que va en contra de la esencia misma de la crítica de cine. Pero, para algunos, solo existe blanco y negro; modelo y antimodelo: la base misma de todo fundamentalismo.

Sin lugar a dudas, de los siete largometrajes, el mejor de todos fue el premiado filme de Claudia Llosa, del cual ya se ha hablado en esta revista. Sin embargo, hubo algunas propuestas interesantes en los otros seis filmes estrenados. Propuestas que muchos críticos quieren negar, al decir, por ejemplo, que Motor y motivo es igual o mejor que Tarata. Afirmar algo así puede implicar dos cuestiones: que existe un serio problema de percepción cinematográfica en quienes lo afirman, o que tales críticos, en su interés por defenestrar el cine peruano, han perdido toda capacidad de crítica y de análisis. La crítica está para jerarquizar a partir de criterios y argumentos, y no de frases hechas del tipo de "todo el cine peruano es igual de malo"; razonamientos que tienen que ver más con el prejuicio que con una visión del cine. El fundamentalismo vuelve a aparecer.

\section{El premio}

La primera cinta estrenada después de La teta asustada fue El premio, sexto largometraje de Alberto "Chicho" Durant, ganadora del premio para posproducción otorgado por el Conacine el 2008. De todos los estrenos nacionales del año, El premio es la película del director más consolidado en cuanto a número de obras realizadas. Los resultados, sin embargo, dejan mucho que desear.

La película es la historia de Antonio (José Luis Ruiz), un profesor provinciano que viaja a Lima para cobrar un premio de lotería, y, de paso, visitar a su hijo Álex (Emanuel Soriano). Las tensiones familiares que implica este reencuentro, además de las provocadas por la atracción que existe entre el joven y su prima (Melania Urbina) son 
las bases sobre las que gira el filme. El problema radica en que la cinta va planteando estos conflictos, sobre todo a partir de lo que los personajes van diciendo y explicando, ilustrándolos, en vez de plasmarlos a partir de la puesta en escena, permitiendo su mayor desarrollo. Esto trae como consecuencia que los personajes sean vistos como meros esquemas simbólicos: nunca se percibe la tensión y el resentimiento que existe entre Álex y Antonio si no es partir de lo que los personajes dicen. O las diferencias que existen entre el personaje de Urbina y Freddy (Paul Ramírez) no están expuestas a partir del ritmo que la puesta en escena podría imprimir, sino de un grupo de gritos y de reclamos que la cinta simplemente ilustra sin profundizar.

Otro elemento desaprovechado es el trabajo con los espacios y las texturas: El premio es una cinta en la cual los personajes se van desenvolviendo en escenarios muchas veces sucios y oscuros. Nada de eso ha sido trabajado por el filme, que prefiere darle a cada locación, a partir del trabajo con la luz, una suerte de uniformidad que termina por quitarle fuerza y relieve a las locaciones que pudieran haber ayudado a aumentar lo urbano, tan latente en el filme.

Todo esto termina por darle a El premio la sensación de ser una maqueta, una cinta que pedía un mayor desarrollo en cada una de sus situaciones. La película mejora bastante en los momentos del robo del dinero, en los cuales se permite que los personajes se guíen por sus acciones más que por la explicación de estas, lo que genera cierta tensión. Algo que hubiéramos esperado en todo el filme.

\section{Tarata}

Tarata es la segunda película de Fabrizio Aguilar, quien había debutado el 2003 con la interesante Paloma de papel. El tema del terrorismo, tocado también en su anterior filme, es ahora tratado usando un hecho real y bastante traumático para los peruanos en general y los limeños en particular: el atentado de la calle Tarata, en el distrito de Miraflores, el año 1992.

Después de su ópera prima, pareciera que Aguilar se propuso hacer una cinta que arriesgara más en su forma de mostrarnos el mundo del terroris- mo. Quizá de ahí venga la elección de Gisela Valcárcel en el rol de Claudia: había que conseguir un gancho para el público ante una propuesta que Aguilar sabía, con plena conciencia, que quizá no tendría mayor éxito de taquilla de otra manera. Por otro lado, tenemos a Daniel (Miguel Iza), el marido de Claudia, quien trabaja en una universidad donde las pintas senderistas se efectúan todos los días, lo que lo comienza a obsesionar. La pareja tiene dos hijos: una niña que vive aterrada pensando en lo que va a ocurrir, y un niño obsesionado con los métodos de seguridad en caso de un ataque terrorista.

\section{Lo que no hay} que perder es la capacidad de pensar las películas peruanas por separado, de verlas y reconocerlas por sus características propias en vez de andar juntándolas

\section{en grupos que las descarten de}

\section{antemano.}

Lo interesante de Tarata es su intención de crear un ambiente en el cual el miedo está presente en todos los actos de la vida cotidiana de los personajes. El gris de las locaciones, la seriedad y lentitud con que los personajes se mueven y actúan, y el ritmo pausado que le va dando el director a todas las situaciones, van creando una especie de incomodidad que invade incluso las situaciones más triviales y relajadas, como pueden ser las reuniones de Claudia con sus amigas o las cenas familiares. El mejor ejemplo de esto quizás sea la escena de la fiesta de amanecida a la que asiste toda la familia: la distancia con la cual el director filma a los personajes va creando un ambiente decadente y extraño, como si el relajo o la distracción no fueran posibles. Cada momento grupal del filme aparece signado por el miedo, por un miedo que está presente en las cosas más intrascendentes.

Otro de los momentos interesantes de la cinta es aquel en el que Daniel y el hijo de su empleada, estudiante de la universidad, son obligados a poner una bandera senderista a través de espacios abstractos, llenos de carpetas puestas una sobre la otra. Tarata genera más interés cuando se la juega por construir ambientes enrarecidos pero construidos a partir de las cosas más comunes.

El problema está en el diseño de los personajes: la obsesión de Daniel por descifrar las pintas terroristas era un tema muy interesante, pero está resuelto a partir de la repetición de la misma acción una y otra vez, sin que genere tensión, lo que le hubiera dado fuerza al personaje. Lo mismo se puede decir del personaje de la hija, que repite una y otra vez su malestar pero sin que se sienta una angustia que esté trabajada desde la puesta en escena. La repetición de estos actos hace que se transformen en meros tics ilustrativos, que nunca producen emoción, lo que hace que sus motivaciones se vayan diluyendo. Lo mismo se puede decir de la intención del filme de pretender abarcar los mayores temas posibles en relación con el terrorismo (arrestos extrajudiciales, toques de queda, coches bomba, ingreso a universidades), termina ilustrándolos todos pero sin mayor desarrollo.

Los defectos son varios, pero hay que reconocerle a Fabrizio Aguilar un riesgo estético que siempre es bienvenido, a pesar de que la cinta resulta menos redonda que su antecesora. Lo cierto es que Tarata es, de todas las películas que comentaremos en este artículo, la única que va ganando en el recuerdo.

\section{Cu4tro}

Parte de otra propuesta arriesgada: la de juntar cuatro cortos dirigidos por jóvenes directores (Frank Pérez-Garland, Christian Buckley, Bruno Ascenzo y Sergio Barrios) y hacer una película que gire alrededor del tema de la ausencia. En una primera impresión hace pensar en Cuentos inmorales, pero si esa cinta tenía como misión mostrarnos diversas caras del costumbrismo y de los personajes limeños de la época, donde el hu- 
mor siempre estaba presente, el tono de Cu4tro es más bien grave, tratando de contarnos historias duras y complejas, que lidian con la muerte, la soledad y la enfermedad.

El primero de los episodios, "4", dirigido por Pérez-Garland, es el mejor del grupo. La premisa es simple: encerrada en su apartamento, una mujer busca lidiar con la ausencia de su marido o pareja, que la ha dejado. Lo que importa en "4" es ver de qué manera la protagonista trata de ocupar ese tiempo de desesperación. La cámara se limita a observar, de forma casi clínica, cómo la protagonista llora, llama por teléfono o hace cualquier cosa que le permita olvidar lo que le ocurre. Es esa mirada impávida y resignada del director hacia su personaje (magníficamente interpretado por Vanessa Saba) y cómo se va desenvolviendo en el espacio, la que va transmitiendo cierta sensación de tristeza.

Christian Buckley dirige “ 3 ", el episodio menos logrado de la serie. El segmento es el único que trata de jugar con el humor a partir de la historia de dos hermanos (Bruno Ascenzo y Natalia Parodi), quienes acaban de perder a su padre y van a una funeraria donde son atendidos por la empleada del local (Katia Condos). El humor nace de los contrastes entre la siempre correcta y burocrática empleada y los sentimientos más feroces de los jóvenes, chocados por el doloroso momento. Sin embargo, el director nunca consigue ni el ritmo ni el timing necesarios para jugar con la incomodidad que nace entre los personajes, lo que hace que el segmento se diluya en una mera anécdota ilustrada.

Por su parte, "2" narra la historia de una joven depresiva y suicida (Gisella Ponce de León) y la relación que establece con el mejor amigo de su padre (Miguel Iza). A Bruno Ascenzo, el director, le interesa el lado más intimista de la situación, tratando de capturar los pequeños momentos de relajo y de tranquilidad en medio de un ambiente sórdido. La distancia con la que el director mira a sus personajes va generando un ambiente triste, como si incluso esos momentos de tranquilidad que tienen entre ellos estuvieran condenados desde un principio. Por momentos se advierte el trazado algo tópico de los persona- jes (sobre todo el de Ponce de León), pero el resultado no está mal.

Finalmente, “1”, de Sergio Barrios, muestra a una pareja homosexual en la cual uno de sus integrantes (Paul Vega) sufre de esclerosis múltiple, por lo que es cuidado por el otro (Renzo Schuller). También se nota un intento del director por crear un ambiente intimista, al mostrar el cariño entre ambos personajes a partir de planos cerrados y fijos, lo que le va dando al corto un aire resignado. Barrios observa los actos y actitudes de sus personajes (ya sea el cariño entre ambos como el encuentro sexual entre el personaje de Schuller con el de Óscar López Arias) a partir de cierta ritualidad, lo cual genera una constante sensación de tristeza. Cu4tro no es un filme parejo, pero cuando deja de lado las afectaciones consigue, por momentos, transmitir la melancolía que buscaban los realizadores.

\section{El delfín y Motor y motivo}

Las propuestas de El delfín: la historia de un soñador, de Eduardo Schuldt, como de Motor y motivo, de Enrique Chimoy, tienen criterios mucho más comerciales. El delfín... es la tercera película del director, quien siempre ha trabajado con la animación. Tanto Piratas en el Callao como Dragones: destino de fuego mostraron un avance en cuanto a la técnica utilizada para generar una mayor calidad en el trazado de los personajes. En ese aspecto, El delfín... (que es la primera película que Schuldt hace con su propia compañía, ya que las anteriores fueron realizadas por Alpamayo Producciones) resulta un paso adelante en relación con esos dos filmes.

Lamentablemente, la calidad de la animación no hace el filme, e incluso puede que sea el asunto menos importante. Cosa que ocurre en El delfín..., que a pesar de su calidad técnica es una película que considera que los niños son incapaces de entender, y que por lo tanto hay que repetirles el mensaje mil veces. Y claro que es positivo un mensaje que dice que nunca hay que renunciar a los sueños, pero si te lo repiten todos y cada uno de los personajes (ya sea Daniel, el delfín, como la tan misteriosa como insufrible voz que sale del mar; y también los personajes secundarios), la cosa se va pareciendo cada vez más a un sermón, dejando de lado cualquier posibilidad de aventura o de diversión. Y no hay nada peor para un niño que lo sermoneen.

Por otro lado, Motor y motivo busca aprovechar el éxito del Grupo 5, conjunto de cumbia fundado en el distrito de Monsefú, provincia de Chiclayo. Ejemplos de películas que se cuelgan del éxito de una agrupación musical hay varios en el Perú: desde Los Shapis en el mundo de los pobres hasta la más reciente: $Y$ qué será de mí, que trata acerca del grupo de tecnocumbia La Joven Sensación.

Pues bien, estamos ante una película que tiene todos los condimentos de esta clase de cintas: desde los problemas amorosos de los integrantes del grupo hasta la banda criminal que busca apoderarse de este, pasando por el viaje que atraviesa el grupo para llegar a su tierra $\mathrm{y}$ todos los problemas que encuentran en el camino.

El problema de Motor y motivo es lo 'primariosa' que se percibe: los sentimientos y emociones de los personajes son expresados como si estuvieran declamando, lo que resulta más bien digno de una velada escolar. Lo mismo se puede decir de las supuestas situaciones tensas que envuelven al individuo que se quiere apoderar del grupo y que los amenaza de todas las maneras posibles: no hay tensión ni conflicto en este hecho, ya que el director se limita a ilustrar cada una de las situaciones pero sin desarrollarlas en lo más mínimo. Cada secuencia está filmada con el mismo tono ilustrativo, lo que hace que cada situación aparezca como inconexa con las otras, y termina en una acumulación sin un ritmo que las cohesione.

Quizá lo que se esconde detrás de esta cinta es la idea de que al espectador hay que darle las cosas lo más fáciles posible: es decir, hacer de cada secuencia un mar de sentimientos declamados para que sepamos que los personajes sufren, un campeonato de gesticulaciones para que quede claro que los malos son bien malos o un concurso de chistes fáciles a los cuales solo les falta la risa grabada propia de la televisión. Nada de esto, creemos, tiene que ver con el cine. Yjustamente por todas estas razones, Motor $y$ motivo fue un doble fracaso: no solo no fue el éxito taquillero esperado sino que, con toda justicia, la podemos con- 
siderar la peor película peruana estrenada el año pasado.

\section{De ollas y sueños}

Dejamos para el final De ollas y sueños, el documental de Ernesto Cabellos, que fue exhibido durante una semana en las salas de la cadena Cineplanet. Es raro que un documental sea estrenado comercialmente, aunque hay que tener en cuenta que toca un tema que está de moda en el Perú: nuestra cocina. La película nos muestra cómo la comida nacional consigue unir a los peruanos, ya sea los que están en el extranjero y a través de ella buscan recordar el país, como de quienes la emplean para rendir homenaje a sus seres queridos fallecidos, pasando por los estudiosos de la culinaria peruana y los que gracias a ella tratan de superar los efecto catastróficos del terremoto de Pisco.

De ollas y sueños, sin embargo, nunca despega de su punto de partida, y lo que sigue durante poco más de una hora es una sucesión de secuencias bastante didácticas que nos van presentando a los entrevistados y su relación con la comida peruana. La emoción que provoca el cocinar y el comer quedan de lado para dejarnos con una serie de testimonios que pueden ser más o menos interesantes, pero que el filme se encarga de ir acumulando solemnemente uno tras otro, como si estuviéramos ante la simple demostración de una idea preconcebida, frente a la cual el director ya tiene una respuesta clara: la comida peruana nos une. De esta manera, se niega uno de los rasgos fundamentales del documental: la posibilidad del descubrimiento y de lo espontáneo. Aquí todo está muy claro desde el principio, y no nos queda otra que presenciar la larga demostración de la idea.

El cine peruano es un tema que siempre dará que hablar. Aparecerán más películas, ya sea entre los estrenos comerciales como en funciones o ciclos especiales, lo que permitirá que el debate continúe. Lo que no hay que perder es la capacidad de pensar cada una por separado, de verlas y reconocerlas por sus características propias en vez de andar juntándolas en grupos que las descarten de antemano. No dejemos que la pereza intelectual gane la partida.
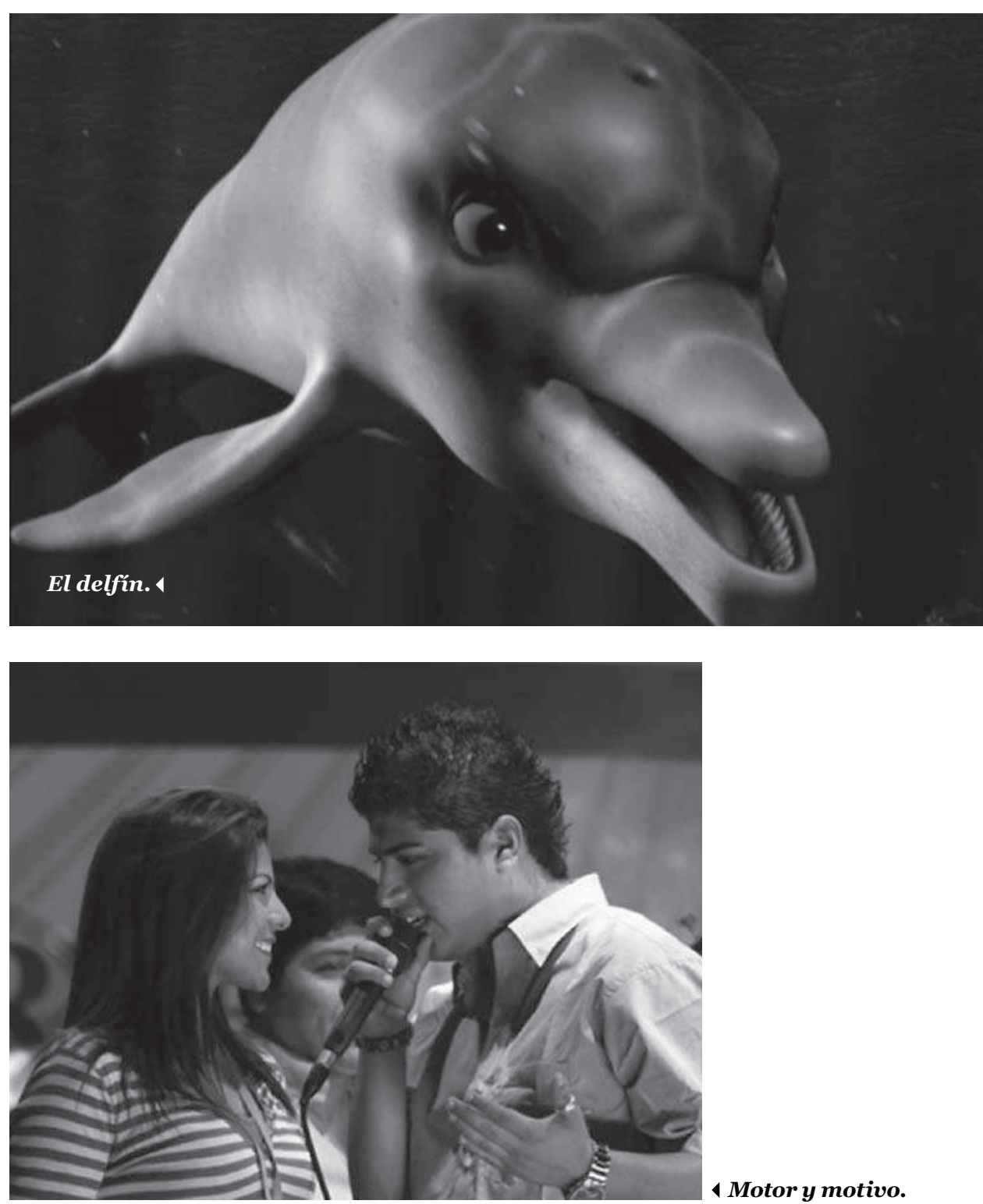

Motor y motivo.

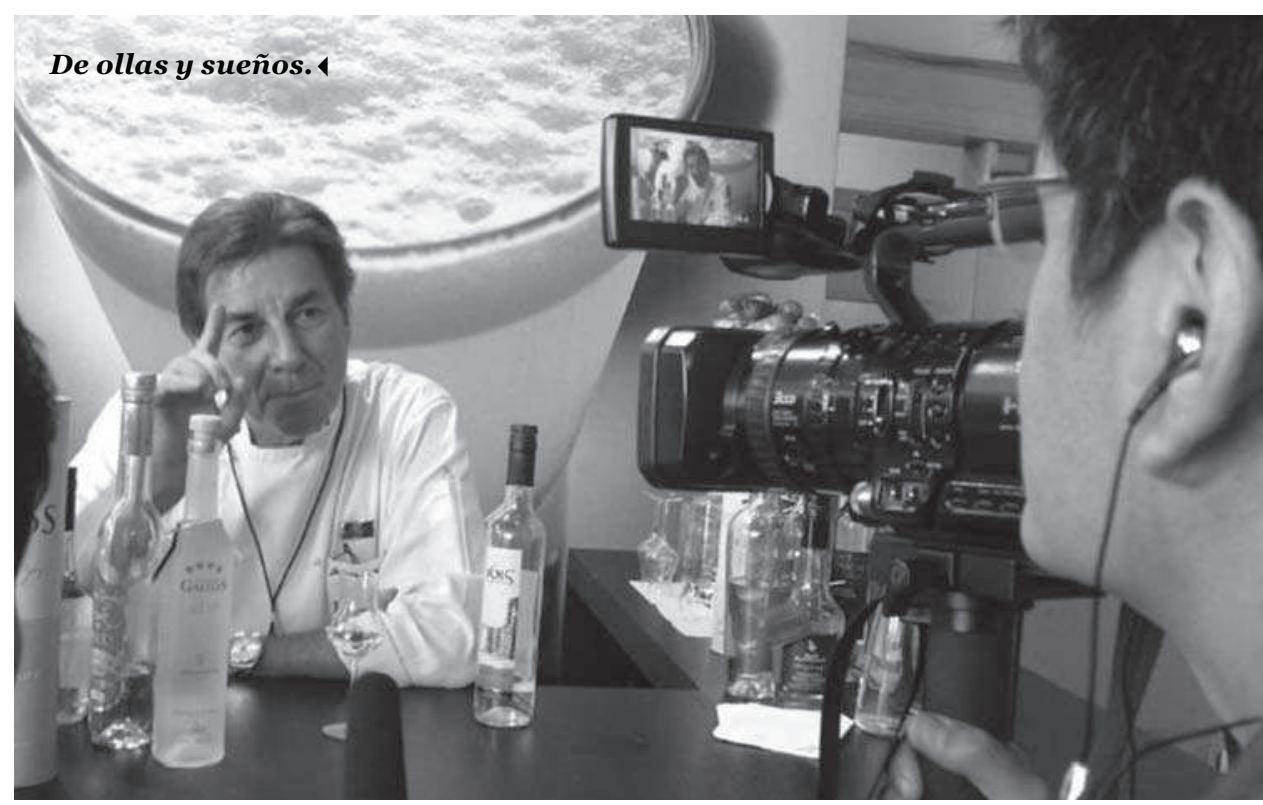

